\title{
FKBP51 regulates decidualization through Ser473 dephosphorylation of AKT
}

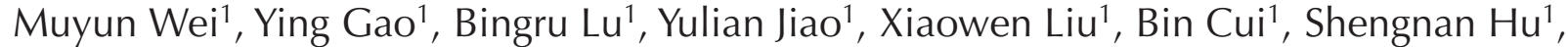 \\ Linying Sun ${ }^{1}$, Shaowei Mao${ }^{1}$, Jing Dong ${ }^{1}$, Lei Yan², Zijiang Chen² and Yueran Zhao ${ }^{1,2}$ \\ ${ }^{1}$ Department of Centre Laboratory, Shandong Provincial Hospital Affiliated to Shandong University, Jinan, China and \\ ${ }^{2}$ Centre for Reproductive Medicine, Shandong Provincial Hospital Affiliated to Shandong University, Jinan, China
}

Correspondence should be addressed to Y Zhao; Email: yranzhao@163.com

\begin{abstract}
Defective decidualization of human endometrial stromal cells (ESCs) has recently been highlighted as an underlying cause of implantation failure. FK-506-binding protein 51 (FKBP51) has been shown to participate in the steroid hormone response and the protein kinase B (AKT) regulation process, both of which are important pathways involved in decidualization. The objective of the present study was to investigate the potential effects and mechanisms of FKBP51 in the regulation of ESC decidualization. By performing immunohistochemical staining on an endometrial tissue microarray (TMA) derived from normal females, we found that FKBP51 expression was much higher in the luteal phase than in the follicular phase in ESCs. Primary ESCs were isolated from patients to build an in vitro decidualization model through co-culture with medroxyprogesterone acetate (MPA) and 8-bromoadenosine (cAMP). SC79, a specific AKT activator in various physiological and pathological conditions, and shRNA-FKBP51 were used to examine the roles of AKT and FKBP51 in decidualization. The Western blot and RT-PCR results showed that FKBP51, insulin-like growth factor-binding protein 1 (IGFBP1) and prolactin (PRL) expression increased in ESCs treated with MPA + CAMP; meanwhile, the level of p-Ser473 AKT (p-S473 AKT) decreased and forkhead box protein O1 (FOXO1A) expression increased. Decidualization was inhibited by the AKT activator SC79 and the transfection of FKBP51-shRNA by affecting protein synthesis, cell morphology, cell growth and cell cycle. Furthermore, this inhibition was rescued by FKBP51-cDNA transfection. The results supported that FKBP51 promotes decidualization by reducing the Ser473 phosphorylation levels in AKT.

Reproduction (2018) 155 283-295
\end{abstract}

\section{Introduction}

Approximately $10 \%-15 \%$ of couples at their reproductive years have experienced infertility. A number of underlying causes of infertility can be partly overcome by in vitro fertilization and embryo transfer (IVF-ET), but the implantation rates remain unsatisfactory because embryos are transferred into a nonreceptive endometrium. Recently, defective decidualization has been highlighted as a major underlying cause of low receptivity (Wang \& Dey 2006, Cha et al. 2012). In humans, decidualization is independent of pregnancy and is primarily a response to ovarian steroids and progesterone during the mid-luteal phase of the menstrual cycle. Adequate decidualization is needed for potential embryo implantation and is the precondition for the establishment and maintenance of pregnancy (Dey et al. 2004, Weimar et al. 2013). Decidualization promotes profound changes in cellular morphology, proliferation capability and gene expression and builds an extracellular matrix (ECM), which is the necessary structure for the blastocyst to invade, anchor itself tightly and absorb nutrients (Strowitzki et al. 2006). The proteins released by decidual cells, such as insulin-like growth factor-binding protein 1 (IGFBP1) and prolactin (PRL), are markers of decidualization levels (Bourdiec et al. 2016). In addition, decidualization can be modelled in vitro using primary endometrial stromal cells (ESCs) co-cultured with medroxyprogesterone acetate (MPA) and 8-bromoadenosine cAMP (8-Br-cAMP), facilitating studies investigating the underlying molecular mechanisms of decidualization (Bombail et al. 2010).

FKBP51 (also called FKBP5) is a $51-\mathrm{kDa}$ protein that was first identified due to its ability to bind the immunosuppressant drugs FK506 and cyclosporine A. This high-molecular-weight immunophilin participates in diverse interactions and numerous functions, particularly those associated with steroid hormone responses (Storer et al. 2011). In certain cultured human cell lines, for example, prostate cancer cells, liver cancer cells (Hep G2) and breast carcinoma cells (T-47D), FKBP51 gene expression is rapidly upregulated by various steroid hormones, including progestin and androgen but not oestrogen (Makkonen et al. 2009, Jaaskelainen et al. 2011). Furthermore, FKBP51 acts as a scaffolding protein 
for protein kinase B (AKT) and $\mathrm{PH}$ domain leucine-rich repeat protein phosphatase (PHLPP) and promotes the dephosphorylation of AKT at Ser473 (Pei et al. 2009). AKT is a serine/threonine protein kinase that regulates various cellular functions, including cell growth, the cell cycle, protein synthesis, glycogen synthesis and metabolism (Yoshino et al. 2003). Regulation of the AKT pathway is closely related to the decidualization progress (Toyofuku et al. 2006). Yin and coworkers demonstrated that the downregulation of p-Ser473 AKT (p-S473 AKT) regulates the decidualization process by directly increasing the expression of forkhead box protein $\mathrm{O} 1$ (FOXO1A), a member of the forkhead box-O family and a nuclear transcription factor involved in cell apoptosis, cell differentiation and cell cycle arrest (Yin et al. 2012). In addition, FOXO1A can physically associate with the progesterone receptor to modulate the expression of decidua-specific genes (IGFBP1 and PRL) and inhibit the cell cycle and proliferation of differentiating ESCs (Takano et al. 2007). These previous studies suggest a possibility that FKBP51 regulates decidualization through the AKT pathway. Therefore, we hypothesized that FKBP51, a protein that participates in steroid hormone responses and the AKT pathway, might be involved in the regulation of decidualization in ESCs. The objective of the present study was to study the expression profile of FKBP51 in the decidualization process using a human tissue microarray and primary ESCs and to examine the potential mechanisms by which FKBP51 regulates decidualization.

\section{Materials and methods}

\section{Immunohistochemistry (IHC) and tissue microarray (TMA)}

A TMA (cat. no. UTN801) of the human endometrium was purchased from Xi'an Alena Biotechnology Ltd., Co. (Xi'an, China), and immunohistochemical staining of FKBP51 was performed by the company. Antigen retrieval was accomplished by heating the sections for $2 \mathrm{~min}$ in citrate buffer at a pH of 6.0. Endogenous peroxidase activity was blocked with $3 \% \mathrm{H}_{2} \mathrm{O}_{2}$ for $30 \mathrm{~min}$. After subsequent blocking with $5 \%$ bovine serum albumin (BSA) for $30 \mathrm{~min}$, the sections were incubated overnight at $4^{\circ} \mathrm{C}$ with primary antibodies against FKBP51 (Abcam) diluted 1:400 in phosphate-buffered saline (PBS) and with PBS alone as a negative control. The sections were then incubated with horseradish peroxidase (HRP)-conjugated secondary antibodies for $20 \mathrm{~min}$ at $37^{\circ} \mathrm{C}$. HRP activity was detected using 3'3-diaminobenzidine for $1 \mathrm{~min}$. The slides were stained with haematoxylin for $5 \mathrm{~min}$ and then dehydrated and mounted using neutral balsam. The immunointensity and percentage of positive ESCs were measured using Image-Pro Plus software (Media Cybernetics Inc., MD, USA; Version 6.0.0.260). We applied a twoscore system for immunointensity and immunopositivity as previously described to quantify FKBP51 immunoreactivity. The following scale was used for the immunointensity score: 0 , negative; 1 , weak; 2 , moderate and 3 , strong. The percentage of immunopositive cells was indicated by the following scores:
$0,1 \% ; 1,1-30 \% ; 2,30-60 \%$ and 3 , more than $60 \%$. The final scores were calculated by multiplying the immunointensity scores by the immunopositivity scores. We then defined low expression as a total score of $0-3$, moderate expression as a total score of 3-6 and high expression as a total score of 6-9 (Xu et al. 2012, Yin et al. 2012). Three different regions in each section were measured in the same manner.

\section{Tissue collection}

Endometrial tissues were collected from 27 patients (age: 31. $4 \pm 4.2$ ) undergoing hysteroscopic electroresection (HE) of endometrial polyps at the Centre for Reproductive Medicine, Shandong Provincial Hospital Affiliated to Shandong University, Jinan, China. All recruited patients had regular menstrual cycles (25-34 days) with confirmation of their menstrual cycle history, nutritional status (BMI: $22.2 \pm 1.2$ ) and normal levels of testosterone, oestradiol and progesterone (detected at the 2nd-4th day of the menstrual cycle). In addition, all 27 patients had not been treated with hormones for at least three months prior to surgery. All samples were obtained in the mid-follicular phase of the menstrual cycle. All participants provided written informed consent before HE. The use of human tissues was approved by the Institutional Review Board of Shandong Provincial Hospital Affiliated to Shandong University, Jinan, China.

\section{Cell culture}

Tissues were washed twice with PBS and minced into pieces of less than $1 \mathrm{~mm}^{3}$. After enzymatic digestion in PBS with $1 \%$ penicillin, $1 \%$ streptomycin and $0.1 \%$ collagenase I (GIBCO $\mathrm{BRL}$, Grand Island, NY, USA) at $37^{\circ} \mathrm{C}$ for $1 \mathrm{~h}$ (shaking the tube every $15 \mathrm{~min}$ ), the digested pieces were filtered through a 100mesh sieve first, and then through a $40 \mu \mathrm{m}$ nylon sieve (Corning) (Sugino et al. 2000, Matsuoka et al. 2010, Salker et al. 2011). The cells passed through the sieve into the filtrates were primarily ESCs, and the cells retained on the nylon sieve were primarily endometrial epithelial cells (EECs). We mixed the primary cells, which were isolated on the same date, into a mixture to ensure that a sufficient number of cells were isolated to allow normal growth. Samples from 20 patients were divided into 7 mixtures (Mix 1-7), and the samples from the remaining 7 patients were used for the preliminary experiments. ESCS and EECs were cultured in Phenol Red-free Dulbecco's modified Eagle's medium (DMEM)/F12 (GIBCO) containing glutamine, antibiotics and $10 \%$ dextran-coated charcoal-stripped foetal bovine serum (CS-FBS) and maintained at $37^{\circ} \mathrm{C}$ and $5 \% \mathrm{CO}_{2}$ in air. Because EECs are notoriously difficult to culture, we seeded the primary EEC cells directly into a 6-well plate and added stimulation at $70-80 \%$ confluence. The ESCs were directly seeded into bottles, grown to confluence and then were passaged for continuous cell culture. The percentage of stromal cells was verified by immunohistochemical staining on fixed cells using the stromalspecific antibody Vimentin (Abcam) and the epithelial-specific antibody CK8+18 (Abcam) at the third generation.

\section{Cell treatment}

To study decidualization, primary ESCs were co-cultured with either $1 \mu \mathrm{M}$ MPA (Sigma) and 0.5 mM 8-Br-cAMP (Sigma) 
(MPA + CAMP) or PBS for 1-4 days Media were changed for fresh media with MPA + CAMP every $48 \mathrm{~h}$. To examine the relationship between FKBP51 expression and progesterone, ESCs were incubated with medium containing $0.5 \mathrm{mM}$ 8-Br-cAMP and different doses of MPA (10nM, $1 \mu \mathrm{M}$, and $100 \mu \mathrm{M}$ ), with or without $1 \mu \mathrm{M}$ RU486 (Sigma) and/or PBS as a control (Cho et al. 2013). The impact of AKT on ESC decidualization was investigated by treating the cells with 1, 4 and $8 \mu \mathrm{g} / \mathrm{mL}$ SC79 (Sigma) for $24 \mathrm{~h}$ before MPA + CAMP treatment. All experiments were performed in triplicate and repeated three times.

\section{Transfection}

The ESCs were transfected with cDNA-FKBP51 (GV230 vector) and shRNA-FKBP51 (GV248 vector) packaged into a lentivirus purchased from GeneChem BioTECH (Shanghai, China) to overexpress and knockdown FKBP51 expression. The cDNA sequences were commercially designed, and the sequences for the shRNA against FKBP51 have been described previously (Pei et al. 2009). After optimizing the experimental conditions, ESCs were seeded onto 24-well plates (30,000 cells/well) and were transfected using $5 \mu \mathrm{g} / \mathrm{mL}$ polybrene (GeneChem) with cDNA-FKBP51 or shRNA-FKBP51 using empty vectors as the respective controls (MOI: 50). The transfection efficiency was examined by flow cytometry. The overexpression and suppression rates were determined by performing Western blotting. FKBP51 cDNA was cloned into pcDNA3.1(+). In the rescue experiments, ESCs, grown to $60 \%$ confluence, were transfected using Lipofectamine 2000 (Invitrogen) with pcDNA3.1(+)/FKBP51 (3 $\mu \mathrm{g}$ in a 6 -well plate) and empty pcDNA3.1(+). All transfections were performed in triplicate and repeated three times.

\section{Western blot analysis}

Total proteins were extracted by RIPA Lysis and Extraction Buffer (Thermo Fisher Scientific) supplemented with protease (Thermo Fisher Scientific) and phosphatase inhibitors (Roche). Protein concentrations were measured by the Micro BCA Protein Assay Kit (Thermo Fisher Scientific). Twenty micrograms of total protein were resolved on a $10 \%$ polyacrylamide gel and then transferred to a polyvinyl difluoride (PVDF) membrane. After blocking with $5 \%$ milk or $5 \%$ BSA for $1 \mathrm{~h}$ at room temperature, the PVDF membranes were incubated overnight at $4^{\circ} \mathrm{C}$ on a shaking table with antibodies against FKBP51, IGFBP1, PRL, vimentin, CK8+18, p-S473 AKT, p-T308 AKT, total AKT and FOXO1A (Abcam) and GAPDH (Santa Cruz). After washing with TBST, the membranes were incubated with HRP-conjugated goat anti-rabbit or anti-mouse secondary antibodies (Santa Cruz) for $1 \mathrm{~h}$ and then detected using the Immobilon Western Chemiluminescent HRP Substrate Kit (Merck Millipore) and the Amersham Imager 600 machine (GE Healthcare). The exposure time of the membrane was automatically detected by the machine. The grey values of the strips were analysed by ImageJ. GAPDH was used as an endogenous control for normalization. Applications of the antibodies are shown in Table 1. All Western blots were performed at least three times from independent experiments, and representative results are shown.

\section{$R N A$ isolation and real-time PCR}

Total RNA was extracted using the Mini BEST Universal RNA Extraction Kit (Takara), then one microgram of total RNA was reverse-transcribed to cDNA using the PrimeScript RT Reagent Kit with gDNA Eraser (Takara). RT-PCR was performed using a Roche A700 sequence detection machine and SYBR GREEN (Takara) to quantify FKBP51, IGFBP1 and PRL mRNA levels. GAPDH was used as an internal control for normalization. The following specific primer pairs were designed using a software programme or as described in previous studies (Yang et al. 2012, Kuroda et al. 2013, Chen et al. 2014): FKBP51: 5'-AAA AGG CCA AGG AGC ACA AC-3' (sense), 5'-TTG AGG AGG GGC CGA GTT C-3' (antisense); IGFBP1: 5'-CGA AGG CTC TCC ATG TCA CCA-3' (sense), 5'-TGT CTC CTG TGC CTT GGC TAA AC-3' (antisense); PRL: 5'-AAG CTG TAG AGA TTG AGG AGC AAA C-3' (sense), 5'-TCA GGA TGA ACC TGG CTG ACT A-3' (antisense) and GAPDH: 5'-GGT ATC GTG GAA GGA CTC-3' (sense), 5'-GTA GAG GCA GGG ATG ATG-3' (antisense).

\section{Proliferation assays}

Cell numbers were evaluated using a Cell Counting Kit-8 (CCK8) (DOJINDO, Kumamoto, Japan) to reflect cell growth. The cells were seeded onto 96-well plates at a density of 10,000 cells/well and cultured for $12 \mathrm{~h}$ to achieve complete adherence before stimulation. After treatment with SC79 and/ or MPA+CAMP for $24,48,72 \mathrm{~h}$, the media were changed to $100 \mu \mathrm{L}$ of fresh media containing $10 \%$ CCK 8 reagent and

Table 1 The application of antibodies.

\begin{tabular}{|c|c|c|c|c|}
\hline \multirow[b]{2}{*}{ Name of antibody } & \multirow[b]{2}{*}{ Manufacturer } & \multirow[b]{2}{*}{ Catalogue } & \multicolumn{2}{|c|}{ Applications } \\
\hline & & & WB & $\mathrm{IHC}$ \\
\hline Anti-IGFBP-1 antibody & Abcam & ab10732 & $1: 500$ & \\
\hline Anti-AKT1(phospho S473) antibody & Abcam & ab81283 & $1: 5000$ & \\
\hline Phospho-AKT (Ser473) Rabbit mAb & CST & $4060 S$ & $1: 2000$ & \\
\hline Anti-FOXO1A antibody & Abcam & ab52857 & $1: 1000$ & \\
\hline Anti-Cytokeratin $8+18$ antibody & Abcam & ab53280 & $1: 50000$ & $1: 250$ \\
\hline Anti-Vimentin antibody & Abcam & ab92547 & $1: 1000$ & $1: 250$ \\
\hline Anti-Prolactin antibody & Abcam & ab110642 & $1: 1000$ & \\
\hline Anti-AKT1/2/3 antibody & Abcam & ab79360 & $1: 1000$ & \\
\hline Anti-FKBP51 antibody & Abcam & ab46002 & $1: 250$ & $1: 400$ \\
\hline Anti-GAPDH antibody & Abcam & ab9485 & $1: 5000$ & \\
\hline
\end{tabular}


incubated for $1 \mathrm{~h}$. The $\mathrm{OD}_{450}$, which reflects the number of viable cells, was detected using a Thermo Scientific Multiskan GO (Thermo Fisher). All CCK8 tests were performed in triplicate and repeated three times.

\section{Flow cytometry}

ESCs were seeded into $75 \mathrm{~mm}^{2}$ bottles. After treatments with MPA + CAMP for another 96h, the ESCs were digested, collected and then fixed with pre-cooled $70 \%$ ethanol at $4^{\circ} \mathrm{C}$ overnight (Li et al. 2014). The fixed cells were washed twice with PBS and stained with BD PI/RNase Staining Buffer (BD Pharmingen, San Diego, CA, USA). The stained cells were detected using BD LSRFortessa to analyse the cell cycle distribution. All flow cytometry tests were repeated three times, and representative results are shown.

\section{Statistical analysis}

The results are presented as the mean \pm S.D. The data were statistically analysed using SPSS for Windows Statistics, version 20 (SPSS). The Mann-Whitney $U$ test was used to analyse immunohistochemical staining scores. ANOVA and MANOVA were used to analyse the CCK 8 results and the expression levels of Western results. Values of $P<0.05$ were considered statistically significant.

\section{Results}

FKBP51 expression profile in the endometrium during in vivo decidualization

To examine alterations in FKBP51 expression in endometrial cells during the human menstrual cycle, we purchased a TMA containing 80 endometria points derived from endometrial biopsies from females with normal cycles and no hormone treatment in the past three months. The TMA included 39 endometria points in the follicular phase and 24 endometria points in the luteal phase (17 points were excluded as uterine smooth muscle or endometrial carcinoma). As shown in Fig. 1A, various degrees of positive immunohistochemical staining for FKBP51 were observed in the epithelial glands and stromal cells. In ESCs, a total of 24 (61.5\%) follicular phase samples and $3(12.5 \%)$ luteal phase samples exhibited low FKBP51 expression. No follicular phase samples but $8(33.3 \%$ ) luteal phase samples showed high FKBP51 expression. Based on these results, FKBP51 expression levels in ESCs were significantly higher in the luteal phase than in the follicular phase $(* * P=0.000)$. However, there was no significant difference in FKBP51 expression between different stages of each phase in ESCs and EECs (Fig. 1B and Table 2).

\section{FKBP51 expression increased during ESC decidualization in vitro}

Immunohistochemical staining for Vimentin and CK8+18 revealed greater than $98 \%$ ESC purity at the third generation, and the ESC lysates did not contain CK8+18 (Fig. 1C and D). Primary ESC in vitro decidualization models had been well established through incubation with MPA+cAMP. Western blotting results (Fig. 1D) revealed remarkable upregulation of IGFBP1 after $\mathrm{MPA}+\mathrm{cAMP}$ treatment for 4 days in ESCs, indicating the successful simulation of decidualization. ESCs under decidualization showed much stronger FKBP51 expression than the control cells. The expression levels of p-S473 AKT declined in decidualization, but the levels of p-T308 AKT remained the same. Furthermore, after treatment, ESCs exhibited obvious morphological changes from spindle-shaped fibroblast-like ESCs to more polygonal-shaped, enlarged secretory cells (Fig. 1E). EECs treated with MPA + cAMP did not change in cell shape but exhibited decreased FKBP51 and p-S473 AKT levels.

To further characterize the effects of decidualization on the expression of FKBP51 and other deciduaspecific proteins, we analysed the proteins extracted from cultured ESCs in the presence of MPA + cAMP at days $0,1,2,3$, and 4 . As shown in Fig. 1F, expression of the marker proteins IGFBP1 and PRL significantly increased with time, suggesting that ESCs treated with MPA + cAMP were undergoing effective decidualization during the 4 days. The expression of FKBP51 remarkably increased with progressing decidualization. In addition, we extracted total RNA from ESCs treated with MPA + CAMP at days 0, 2 and 4. The mRNA levels of FKBP51, IGFBP1 and PRL were detected using RT-PCR. As shown in Fig. 1G, MPA + cAMP strongly and synchronously increased FKBP51, IGFBP1 and PRL mRNA levels. FKBP51 mRNA levels in treated cells showed fold increases of $39.12 \pm 6.66$ and $29.28 \pm 0.35$ at 2 and 4 days, respectively.

To analyse the dose dependence of FKBP51 on MPA, ESCs were incubated with various doses of MPA $\left(10^{-8}, 10^{-6}\right.$ and $\left.10^{-4} \mathrm{M}\right)$ in the presence of CAMP for 4 days. According to the Western blotting results, MPA + cAMP increased FKBP51 expression in a dosedependent manner (Fig. 1H). To determine whether the progesterone receptor is necessary for the induction of FKBP51 protein expression during decidualization, ESCs were cultured for 4 days with MPA + CAMP as well as RU486, a progesterone-competitive antagonist with high affinity for PR. Treatment with RU486 blocked the induction of FKBP51 by MPA + CAMP (Fig. 1H).

\section{Reduced activation of the AKT pathway ensured ESC decidualization}

Previously, we observed levels of p-S473 AKT, p-T308 AKT and total AKT in ESCs undergoing MPA + CAMP treatment compared with control cells. To investigate the effects of the AKT pathway on ESC decidualization, we performed Western blotting on lysates extracted from cultured ESCs in the presence of MPA+ CAMP at days $0,1,2,3$ and 4 to measure the proteins of the 


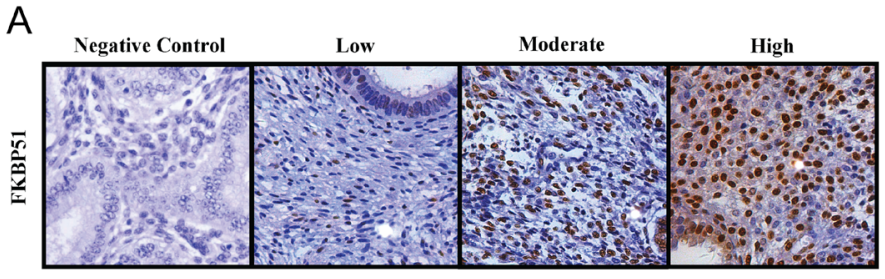

C

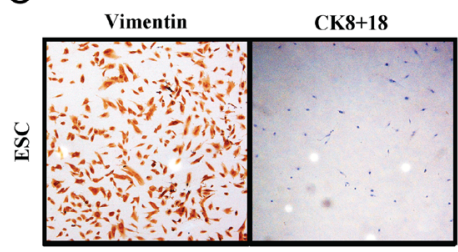

$\mathrm{E}$

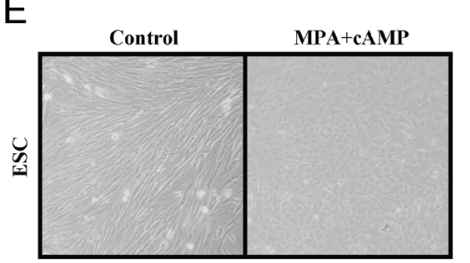

$\mathrm{F}$

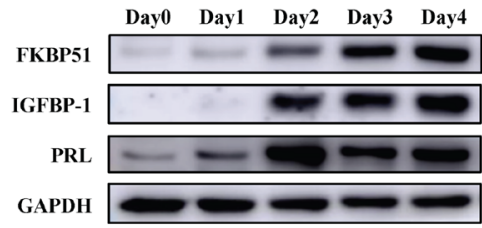

G

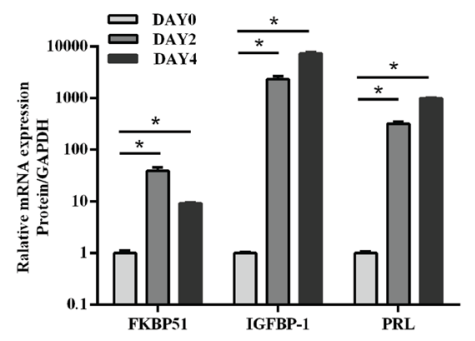

D

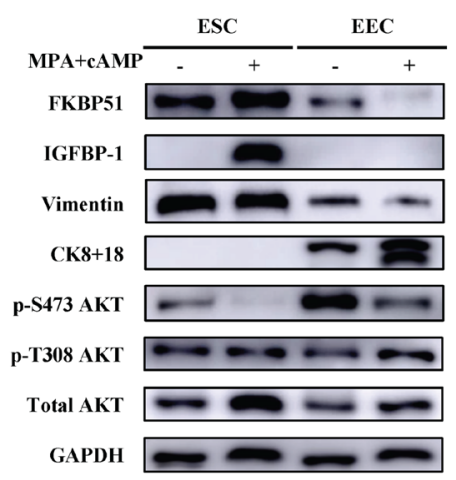

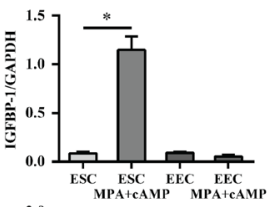
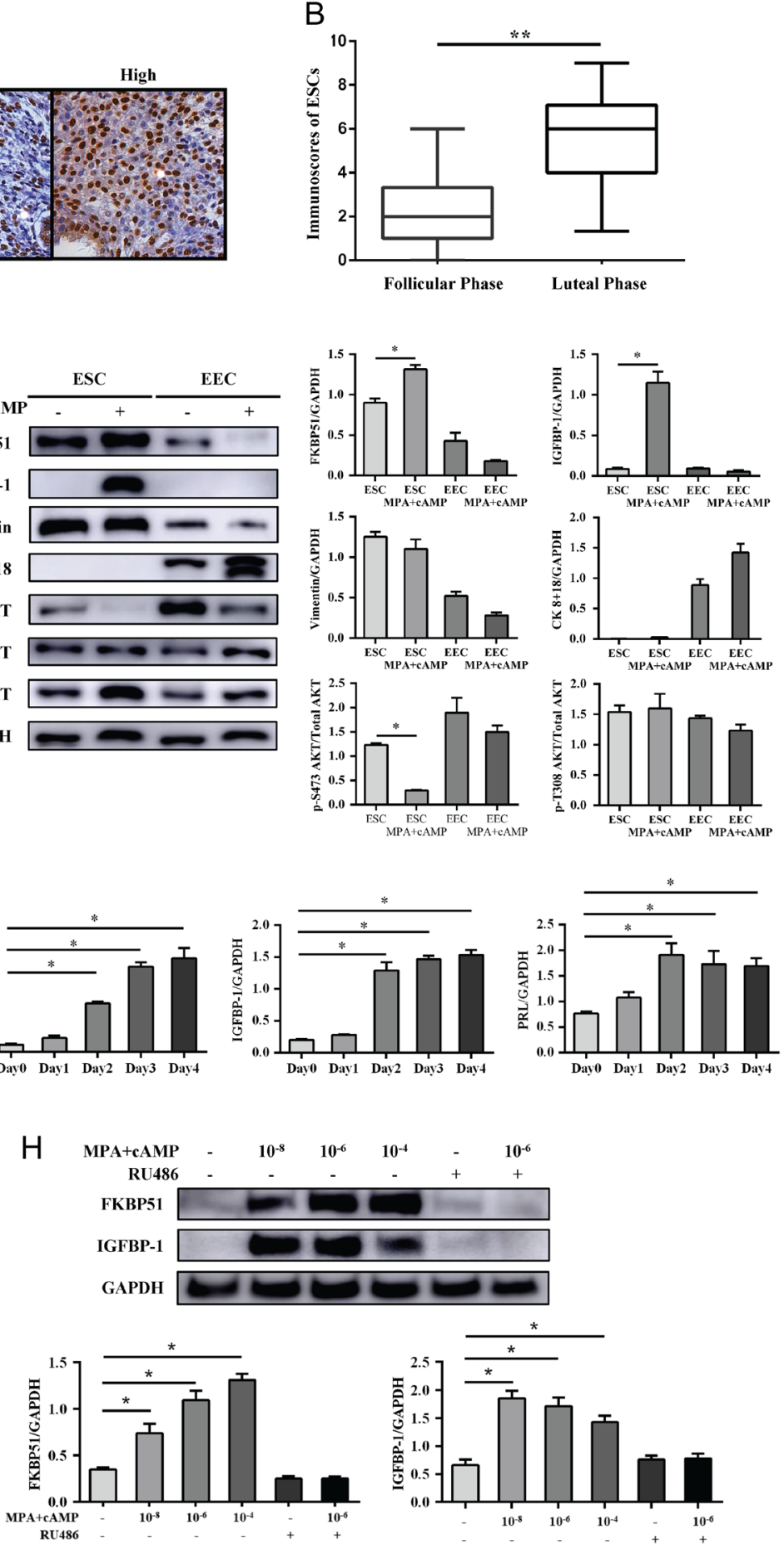

Figure 1 FKBP51 expression during decidualization in vivo and in vitro. (A) Pictures of different expression levels of immunohistochemical staining of FKBP51 and negative controls on the tissue microarray UTN801. Original magnification, $\times 400$. (B) Semi-quantification of FKBP51 expression in ESCs was significantly higher in the luteal phase than in the follicular phase $(* * P=0.000)$. (C) Immunohistochemical staining of vimentin and CK8+18 in ESCs in the third generation showed that the ESC purity was more than $98 \%$. Original magnification, $\times 200$. (D) ESCs and EECs were treated with MPA + CAMP for 4 days. Protein levels were measured by performing a Western blot analysis $(* P<0.05$; repeated in Mix $1,2,3)$. (E) The morphology of ESCs co-cultured with or without MPA + CAMP for 4 days is shown. Original magnification, $\times 200$. (F) The expression of FKBP51, IGFBP-1 and PRL during MPA + CAMP-induced decidualization at days $0,1,2,3$ and 4 was analysed by Western blot analysis $\left({ }^{*} P<0.05\right.$; repeated in Mix 2, 3, 4, 5). (G) Relative mRNA levels of FKBP51, IGFBP-1, and PRL on days 0,2 and 4 were detected using real-time PCR $\left({ }^{*} P<0.05\right.$; repeated in Mix $\left.2,3,4,5\right)$. (H) ESCs were cultured with $0.5 \mathrm{mM} \mathrm{cAMP}$ and various doses of MPA $\left(10^{-8}, 10^{-6}\right.$ and $10^{-4} \mathrm{M}$ ) with or without $1 \mu \mathrm{M}$ RU486 for 4 days. FKBP51 and IGFBP-1 levels were detected by performing a Western blot analysis $\left({ }^{*} P<0.05\right.$; repeated in Mix 3, 4, 5). 
Table 2 FKBP51 expression in endometrium samples of TMA.

\begin{tabular}{|c|c|c|c|c|c|c|c|c|c|}
\hline & \multirow[b]{2}{*}{ No. } & \multicolumn{4}{|c|}{ FKBP51 expression in ESCs } & \multicolumn{4}{|c|}{ FKBP51 expression in EECs } \\
\hline & & Low & Moderate & High & $P$ & Low & Moderate & High & $P$ \\
\hline \multicolumn{10}{|l|}{ Age } \\
\hline$<30$ & 7 & 3 & 4 & 0 & 0.483 & 4 & 1 & 2 & 0.515 \\
\hline$\geq 30,<50$ & 31 & 11 & 15 & 5 & & 8 & 17 & 6 & \\
\hline$\geq 50$ & 25 & 13 & 9 & 3 & & 13 & 6 & 6 & \\
\hline \multicolumn{10}{|l|}{ Phase } \\
\hline Follicular & 39 & 24 & 15 & 0 & 0.000 & 18 & 15 & 6 & 0.521 \\
\hline Luteal & 24 & 3 & 13 & 8 & & 10 & 8 & 6 & \\
\hline
\end{tabular}

AKT pathway. As shown in Fig. 2A, ESCs treated with MPA + cAMP exhibited lower p-S473 AKT levels than control ESCs. In addition, p-T308 AKT levels and total AKT expression levels did not show clear trends from day 0 to 4 . Furthermore, we detected the expression of FOXO1A, an important protein in decidualization as well as a downstream protein of p-S473 AKT. Expression of FOXO1A gradually increased from day 0 to day 4 . These data suggested that the AKT pathway may be a predominant signalling pathway to ensure adequate decidualization.

To confirm the role of the AKT pathway in the decidualization response, the AKT activator SC79 was used in co-culture with ESCs in the presence or absence of MPA + cAMP. As expected, SC79 increased p-S473 AKT levels, whereas total AKT levels remained the same (Fig. 2B). Treatment with various doses of $\operatorname{SC79}(1,4$ and $8 \mu \mathrm{g} / \mathrm{mL})$ and MPA + CAMP decreased IGFBP1 expression in a dose-dependent manner; the expression levels of FOXO1A were also simultaneously decreased, suggesting that decreased activation of the AKT pathway is required for ESC decidualization (Fig. 2C).

\section{Effects of FKBP5 expression on decidualization}

We further explored the consequences of disrupted FKBP51 expression during decidualization. First, we transfected ESCs with lentiviruses containing an empty vector as a negative control (FKBP51-NC), shRNAFKBP51 (FKBP51-KD) to knockdown FKBP51 and CDNA-FKBP51 (FKBP51-OE) to overexpress FKBP51. Flow cytometry analysis showed that the transfection efficiency of the negative control lentivirus was $81.5 \% \pm 4.2$, and the transfection rates of the knockdown lentiviral vector and overexpression vectors were $91.5 \% \pm 3.4$ and $98.7 \% \pm 1.6$, respectively (Fig. 3A). Second, we detected the proteins affected by FKBP51 knockdown and overexpression in transfected cells. As shown in Fig. 3B, in FKBP51-KD ESCs, FKBP51 expression was suppressed by $52.90 \pm 9.23 \%$, and p-S473 AKT levels increased, which was accompanied by the downregulated expression of FOXO1A. In FKBP51-OE ESCs, the effects of FKBP51 overexpression were remarkable, leading to decreased p-S473 AKT levels and a significant increase in FOXO1A.
By performing Western blot analysis on the lysates of FKBP51-NC and FKBP51-KD ESCs treated with $M P A+C A M P$ for 0,2 and 4 days, we detected the impact of FKBP51 knockdown on ESCs during decidualization. Figure 4A shows that FKBP51 expression in FKBP51-NC ESCs exhibited an increasing trend during decidualization, but this trend was strongly inhibited in FKBP51-KD ESCs. The upregulated expression of the decidualization markers IGFBP1 and PRL in response to MPA + CAMP was also reduced by FKBP51 suppression. In addition, p-S473 AKT levels increased and FOXO1A expression decreased. The typical morphological changes accompanying decidualization disappeared in FKBP51-KD ESCs (Fig. 4B). Moreover, a CCK8 kit was employed to construct proliferation curves for FKBP51-NC and FKBP51-KD ESCs in the presence or absence of MPA+CAMP. As shown in Fig. 4C, the proliferation of ESCs transfected with a negative control virus was remarkably suppressed after treatment with MPA + CAMP $(* * P<0.01)$, but in FKBP51-KD ESCs, the proliferation of ESCs did not differ significantly with or without MPA+CAMP treatment (except at $72 \mathrm{~h}$ ). Furthermore, the transformation of ESCs into decidual cells requires a cell cycle change. According to the flow cytometry results (Fig. 4D), FKBP51 knockdown reduced cell cycle arrest at the G1/S phase (99.55\%-86.08\%), which is required for ESC decidualization and the inhibition of stromal cell differentiation. All these results suggested that the in vitro decidualization induced by MPA + CAMP was inhibited via FKBP51 suppression in FKBP51-KD ESCs.

\section{FKBP51 overexpression rescued the suppressive effects of SC79 and FKBP51 ShRNA}

FKBP51 overexpression (>100\%) in ESCs notably suppressed p-S473 AKT levels and upregulated FOXO1A, as verified by Western blotting. As shown in Fig. $5 \mathrm{~A}$, the inhibitory effects of FKBP51 knockdown on IGFBP1, PRL and FOXO1A were rescued by the FKBP51 overexpression caused by pcDNA3.1(+)/FKBP51. To confirm whether FKBP51 knockdown suppresses ESC decidualization by targeting $\mathrm{p}-\mathrm{S} 473$ AKT and the AKT pathway, we performed another rescue experiment using FKBP51-OE ESCs treated with MPA+CAMP in the presence and absence of SC79 $(4 \mu \mathrm{g} / \mathrm{mL})$. As shown 

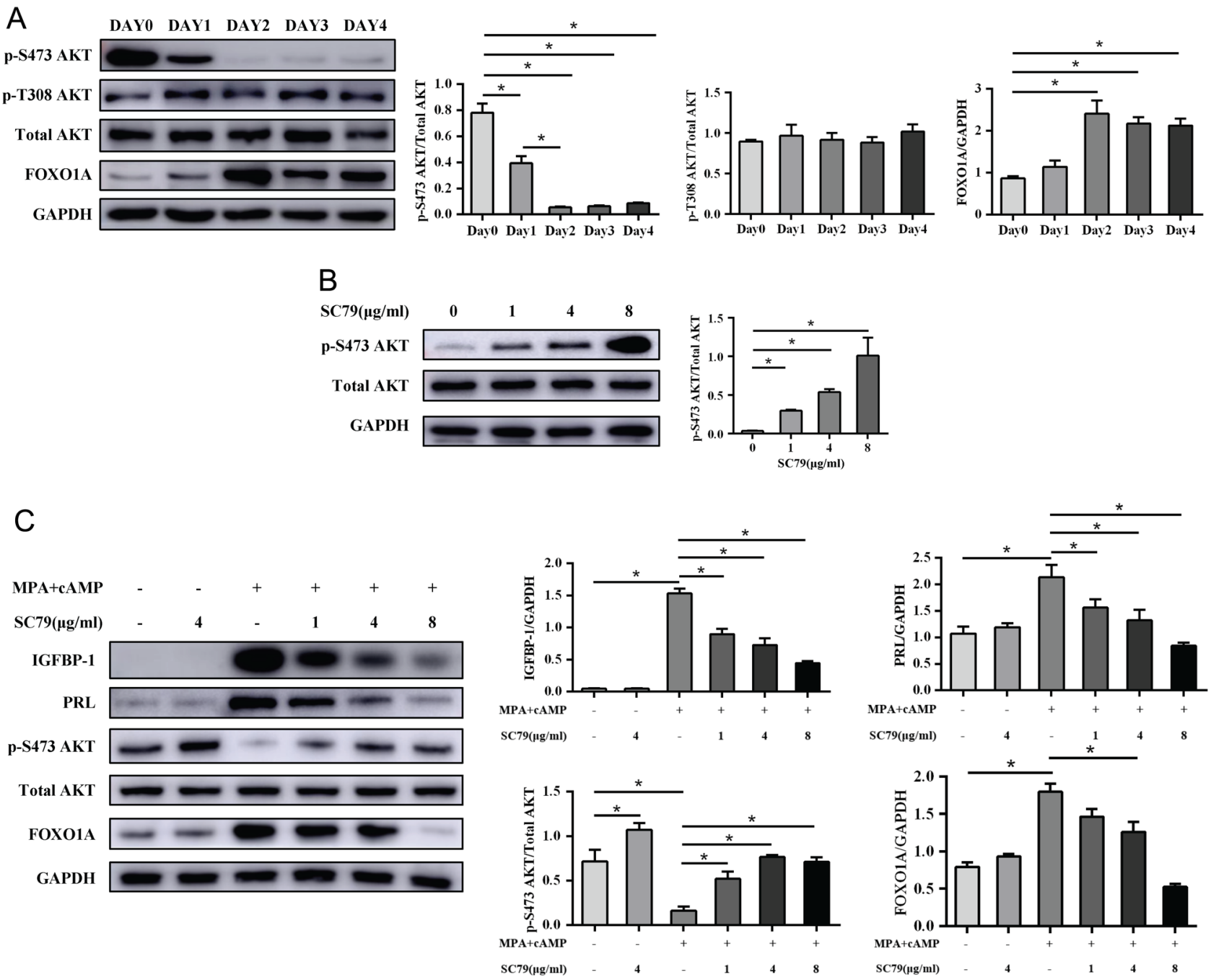

Figure 2 Expression and regulation of the AKT pathway during decidualization. (A) ESCs were treated with MPA + CAMP for $0,1,2,3$ and 4 days. The phosphorylation levels at the Ser473 and Thr308 sites in AKT and the level of FOXO1A were detected by performing a Western blot analysis $\left({ }^{*} P<0.05\right.$; repeated in Mix 2, 3, 4, 5). (B) We collected the proteins of ESCs treated with different doses of SC79 $(1,4 \mathrm{and} 8 \mu \mathrm{g} / \mathrm{mL})$ for $24 \mathrm{~h}$ and performed Western blot analysis to detect the level of p-S473 AKT $(* P<0.05$; repeated in Mix 3, 4, 5). (C) To confirm the effects of AKT on decidualization, we treated ESCs with different doses of SC79 $(1,4$ and $8 \mu \mathrm{g} / \mathrm{mL})$ and/or MPA + CAMP for 4 days and collected total protein. P-S473 AKT levels and the expression of total AKT, FOXO1A, IGFBP-1 and PRL were detected by Western blot analysis $(* P<0.05$; repeated in $\operatorname{Mix} 3,4,5)$.

in Fig. 5B, SC79 inhibited IGFBP1, PRL and FOXO1A upregulation induced by MPA+CAMP, but FKBP51 overexpression recovered the expression of these decidualization marker proteins. A CCK8 test performed with FKBP51-NC and FKBP51-OE ESCs treated with PBS as a control or MPA + CAMP for 4 days, with or without $24 \mathrm{~h}$ of pretreatment with SC79 $(4 \mu \mathrm{g} / \mathrm{mL})$, also indicated that SC79 blocked the decreased proliferation induced by MPA + CAMP, but these inhibition effects were rescued by FKBP51 overexpression (Fig. 5C).

\section{Discussion}

To our knowledge, the present study is the first to implicate FKBP51 as an indispensable element in supporting the decidualization of ESCs. Decidualization involves a complicated and highly interactive set of interacting signalling pathways that regulate the effects of sex steroid communication via transcription factors and cytokines, resulting in controlled cell growth, cell cycle changes and stroma cell decidual differentiation in the endometrium (Tan et al. 2002, Curry \& Osteen 2003). Decidualized ESCs play a role in ensuring the uterine receptivity to implantation, while defective decidualization contributes to infertility (Das 2009).

Our results first demonstrate that the expression of FKBP51 is altered during the decidualization of ESCs both in vivo and in vitro. The significant difference in FKBP51 expression observed between the follicular and luteal endometria by the TMA shows that FKBP51 expression 

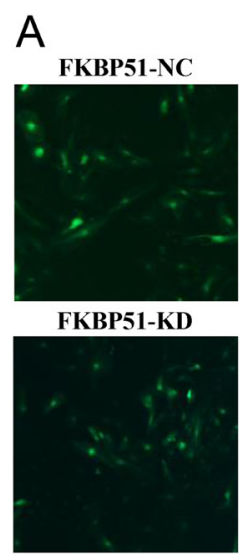

FKBP51-OE
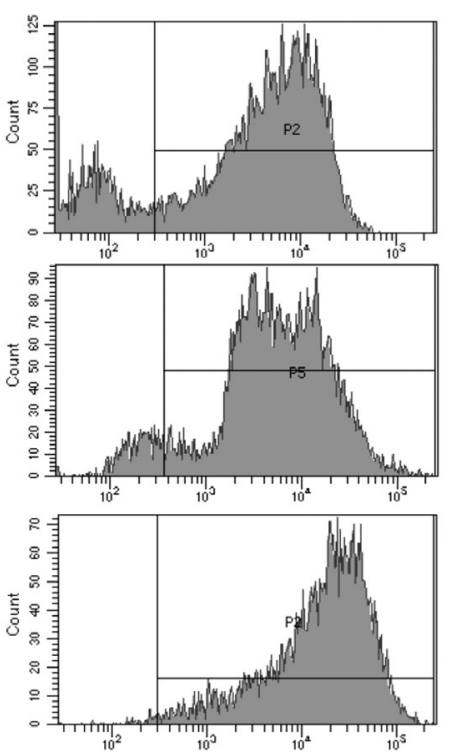

B
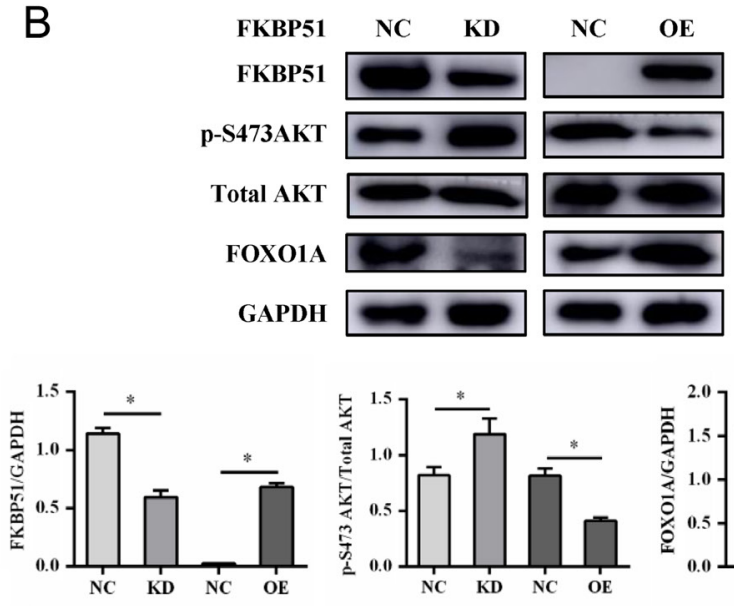

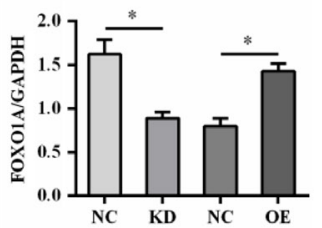

Figure 3 Knockdown and overexpression of FKBP51 in cultured ESCs. (A) ESCs were transfected by lentiviruses containing an empty vector as a negative control (FKBP51-NC), shRNA-FKBP51 (FKBP51-KD) or cDNA-FKBP51 (FKBP51-OE) at an MOI of 50. Pictures of the fluorescent transfected cells were obtained, and the transfection rate was detected using flow cytometry. (B) The suppression and overexpression rates of transfected ESCs were detected by performing a Western blot analysis. In addition, p-S473 AKT levels and levels of the downstream protein FOXO1A were simultaneously examined by a performing Western blot analysis $\left({ }^{*} P<0.05\right.$; repeated in Mix $\left.4,5,6,7\right)$.

is upregulated in vivo during human decidualization. As previously described, decidualization is mainly induced by progesterone during the mid-luteal phase in humans, regardless of the presence or absence of an embryo; decidualization in humans is clearly different than that, which occurs in mice. Mouse decidualization is initiated through both steroid hormones and the presence of an embryo or a surrogate stimulus occurring near the location of embryo implantation (Yang et al. 2006). Thus, we believe that our initial tissue array results suggest that FKBP51 have more functions in humans than in mice, although studies using female FKBP51 genetically modified mice showed that these mice were fertile and normal (Stechschulte et al. 2016). Our in vitro data provide evidence that FKBP51 expression is increased in a decidualization model. These results agree with the finding that FKBP51 can be strongly upregulated by androgen, glucocorticoid, mineralocorticoid and progesterone signalling (Jaaskelainen et al. 2011). In previous studies investigating the functions of ESCs, FKBP51 mRNA sharply increased after treatment with MPA, as confirmed by a whole genome microarray analysis (Guzeloglu Kayisli et al. 2015). Studies in T-47D and HepG2 cells indicate FKBP51 gene expression is directly regulated by progesterone (Hubler et al. 2003). In the present study, progesterone induced a time- and dose-dependent upregulation of FKBP51 expression, which could be blocked by RU486. Previous studies showed that FKBP51 plays a role as one of the components that regulate both progesterone receptor and glucocorticoid receptor (GR) activity (Sinars et al. 2003, Caldwell et al. 2010). RU486 is the most widely used PR antagonist, has a high affinity for PR, competes with progesterone (Wardell et al. 2010) and is also an antagonist of the GR (Rearte et al. 2010). The MPA-induced increase can be blocked by the PR antagonist RU486, which suggests that MPA may activate FKBP51 expression via a steroid hormone receptor. Expression of FKBP51 appears important for adequate decidualization because transfection with FKBP51 shRNA markedly reduced the induction of decidualization at both the protein and phenotype levels, as indicated by cell images and reduced expression of IGFBP1 and PRL. However, FKBP52, another large immunophilin FKBP, has a similar structure as FKBP51 and also plays a role in decidualization. Both proteins are Hsp90 co-chaperones that modify steroid hormone receptor activity but have diverse regulation in steroid hormone receptor signalling (Storer et al. 2011). FKBP52 governs normal PR function in the mouse uterus (Tranguch et al. 2006). Transgenic FKBP52-null mice have complete implantation failure, although ovulations are normal (Tranguch et al. 2007). Women with endometriosis have low levels of FKBP52 expression, leading to infertility mainly due to impaired decidualization through homeobox A10(HOXA10)regulated FKBP52 expression (Yang et al. 2012). In the present study, the potential roles of FKBP51 and FKBP52 in the human menstrual cycle were detected by immunohistochemical staining of the TMA, but we did not observe a significant difference in the expression of FKBP52 between the follicular phase and the luteal phase 

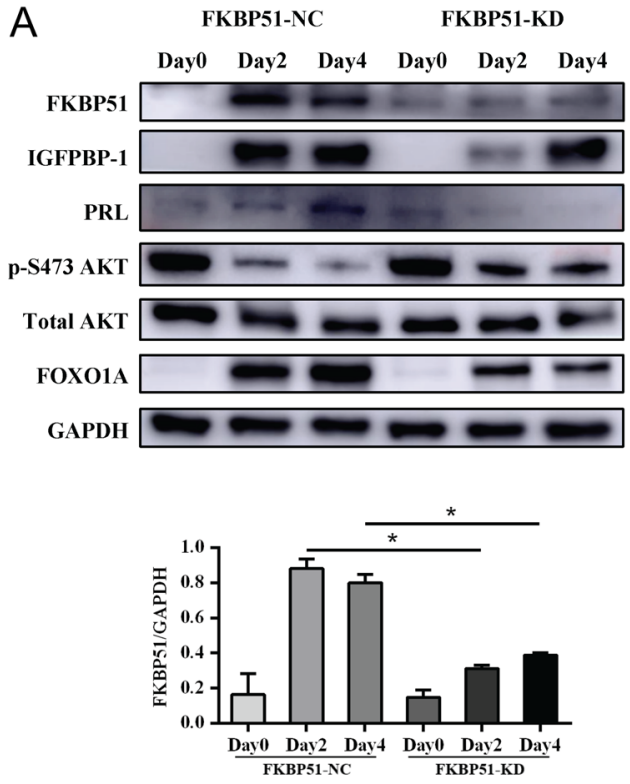

B

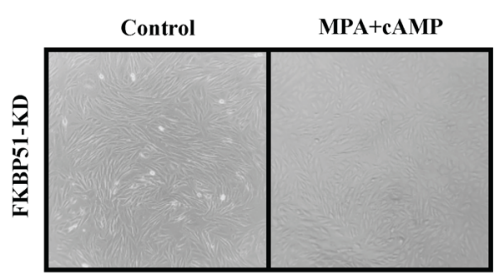

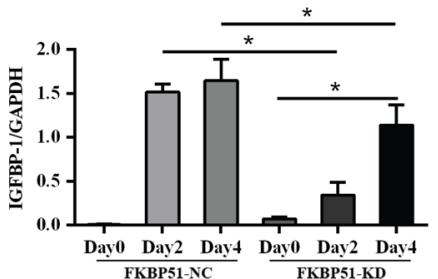
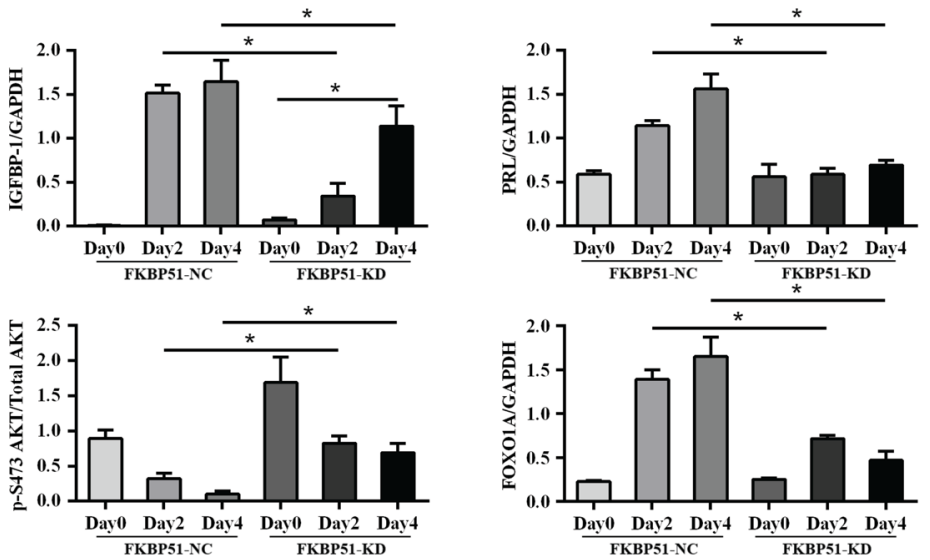

C
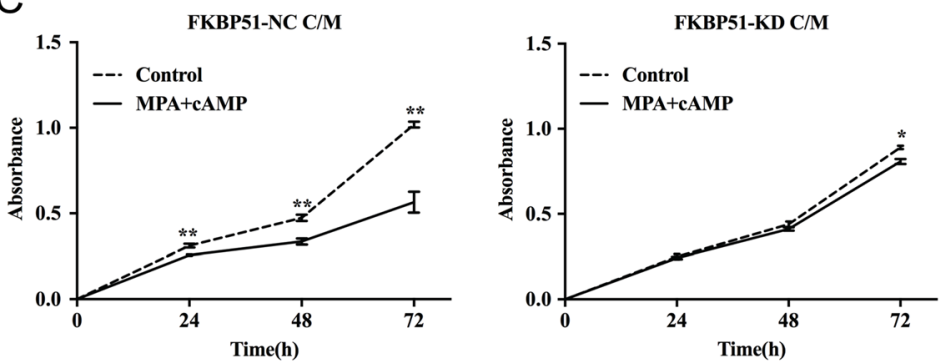
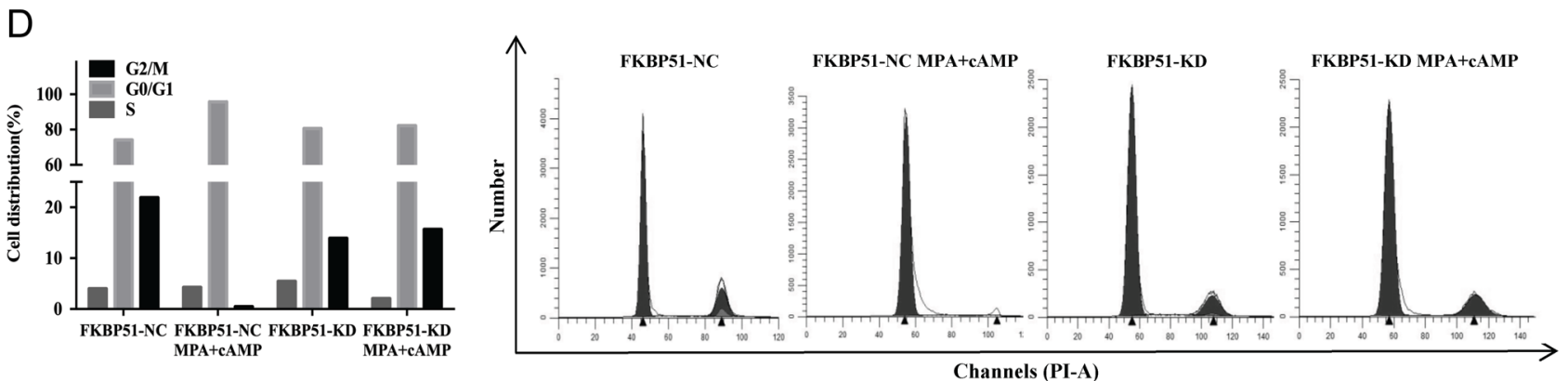

Figure 4 The effects of FKBP51 knockdown during in vitro decidualization. (A) ESCs transfected with shRNA-FKBP51 (FKBP51-KD) and empty vectors (FKBP51-NC) were co-cultured with MPA + cAMP, and total protein was extracted at days 0, 2 and 4. Differences in protein expression during decidualization between FKBP51-NC and FKBP51-KD were detected by performing a Western blot analysis $\left({ }^{*} P<0.05\right.$; repeated in Mix 4, 5, 6, 7). (B) Images of FKBP51-KD ESCs treated with PBS as control or MPA + cAMP for 4 days. Original magnification, $\times 200$. (C) The proliferation ability of FKBP51-NC and FKBP51-KD ESCs during decidualization was investigated by performing a CCK8 assay $(* P<0.01$, ${ }^{* *} P<0.05$; repeated in Mix 4, 5, 6). (D) The effects of FKBP51 on the cell cycle. FKBP51-NC and FKBP51-KD ESCs were incubated with or without MPA + CAMP for 4 days, collected and stained with PI for cell cycle analysis by flow cytometry. The percentages of cells in different phases and the cell distribution are shown in the bar graph.

(data not shown). The results suggest that stable FKBP52 expression is required for decidualization in a normal menstrual cycle, and the lack of FKBP52 in a disease state will lead to impaired decidualization.

Deficient AKT levels disrupt the intracellular balance between survival and death, affecting numerous biochemical processes. In type 1 endometrial cancer, the cell-autonomous hyperactivation of AKT is essential for triggering endometrial carcinoma in epithelia (Memarzadeh et al. 2010). In endometriosis, the AKT pathway is hyperactivated, contributing to the pathogenesis of progesterone resistance and the attenuation of decidualization through its downstream target (Cinar et al. 2009, Velarde et al. 2009). In 
A
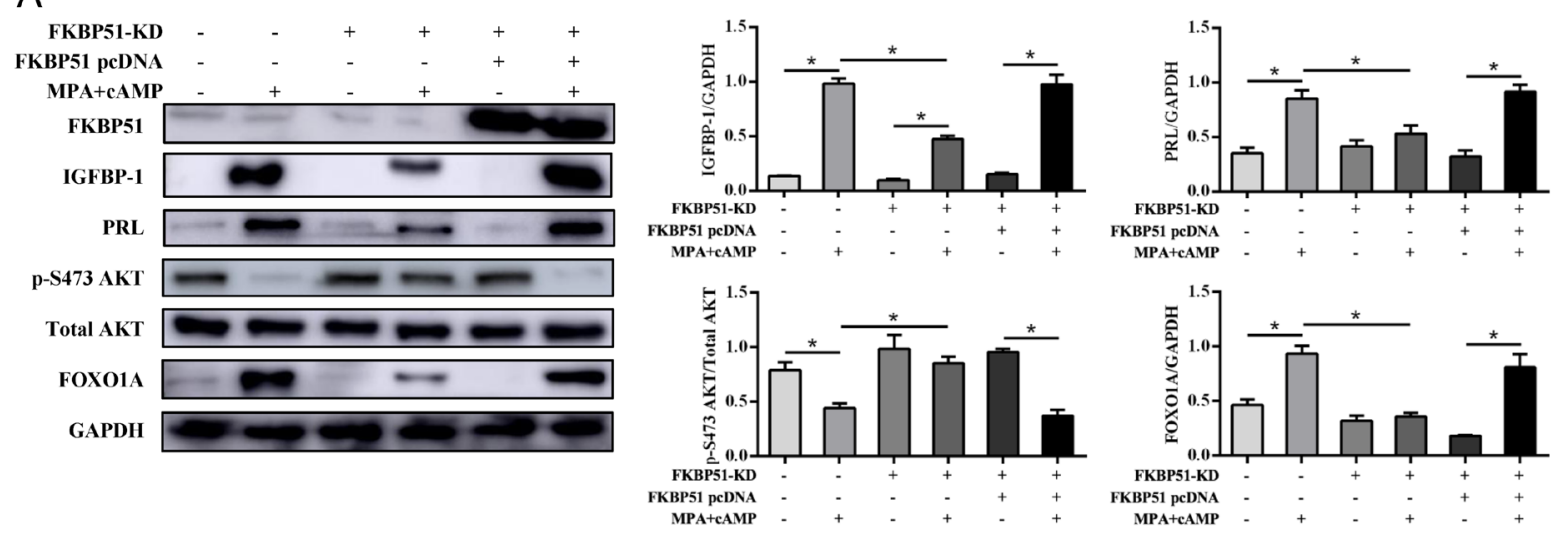

B
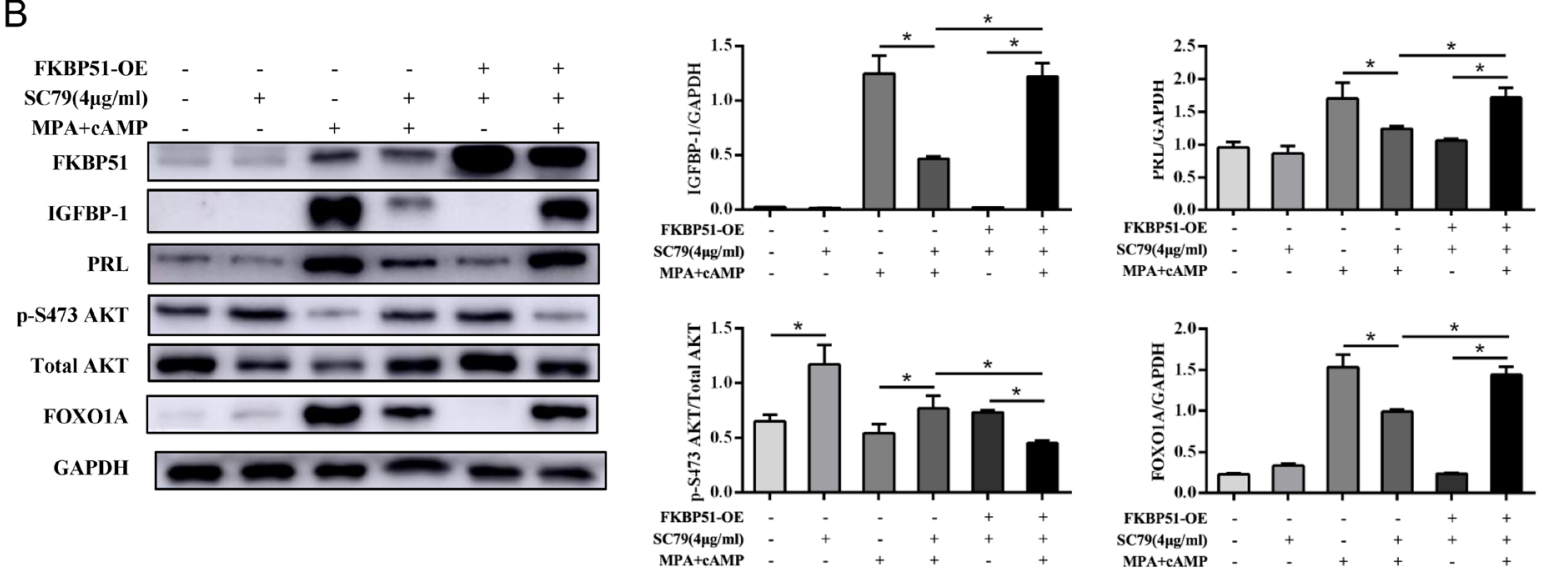

C
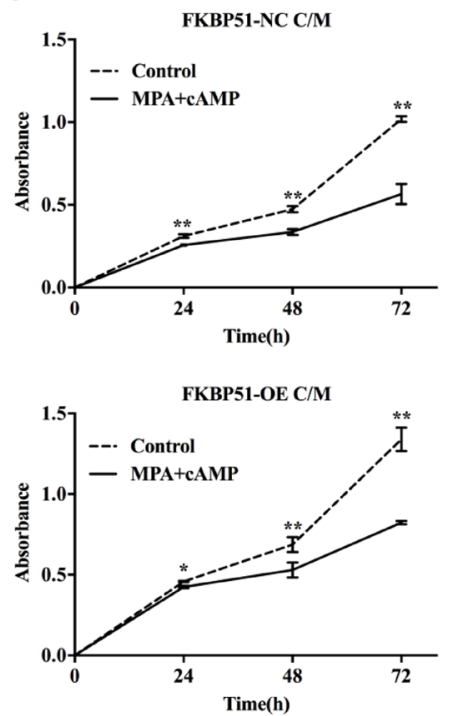
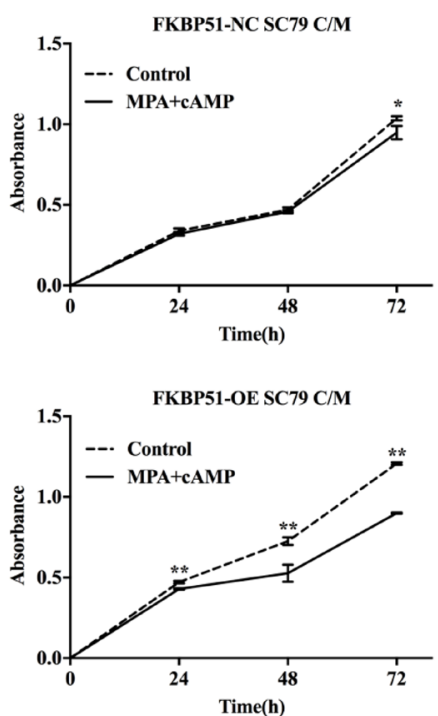

D

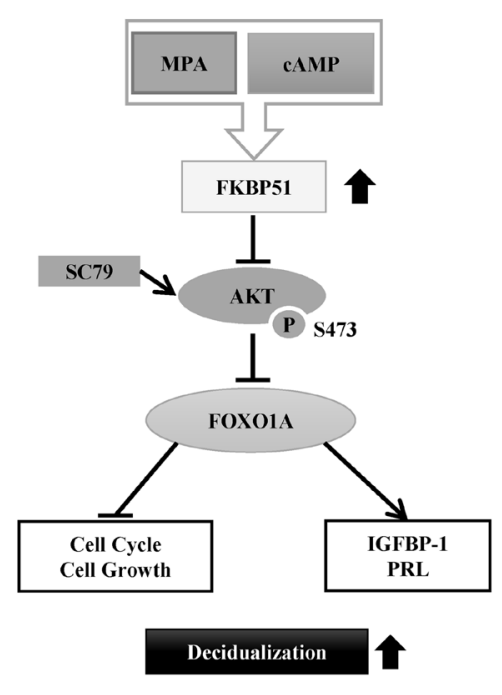

Figure 5 Rescue effects of FKBP51 overexpression. (A) FKBP51-NC and FKBP51-KD ESCs were seeded onto six-well plates and transfected with a pcDNA3.1(+)/FKBP51 plasmid or empty pcDNA3.1(+) for $12 \mathrm{~h}$. After incubation for an additional $48 \mathrm{~h}$, the cells were treated with PBS as a control or MPA + CAMP for 4 days. Protein expression levels were detected by performing Western blot analysis $\left({ }^{*} P<0.05\right.$; repeated in Mix 5, 6, 7). (B and C) FKBP51-NC and FKBP51-OE ESCs were seeded onto six-well plates and treated with PBS as a control or MPA + CAMP for 4 days, with or without 24-h pretreatment with SC79 $(4 \mu \mathrm{g} / \mathrm{mL})$. Proteins were analysed by Western blotting, and changes in proliferation were detected by performing a CCK8 assay $\left({ }^{*} P<0.01,{ }^{*} P<0.05\right.$; repeated in Mix $\left.5,6,7\right)$. (D) The signalling pathway underlying FKBP51 regulation of decidualization is demonstrated in the present study. 
addition, the activation of decidualization-specific genes requires not only PR but also FOXO1A, a member of the forkhead transcription factor subfamily, which is one of the direct targets of p-S473 AKT (Takano et al. 2007). FOXO1A plays a significant role in decidualization, including interacting with progesterone receptors to initiate decidualization and promote IGFBP1, PRL and decorin (DCN) expression (Kim et al. 2005, Buzzio et al. 2006, Labied et al. 2006). The modulation of the AKT pathway is of critical importance to the establishment of decidualization in vivo and in vitro (Hirota et al. 2010, Mori et al. 2011). Total AKT protein is always stable in any stage of the menstrual cycle, but the levels of p-S473 AKT show decrease in mid-secretory endometria (Toyofuku et al. 2006). Primary ESCs undergoing decidualization through progesterone supplementation exhibit reduced levels of p-S473 AKT (Yoshino et al. 2003, Yin et al. 2012). The observed significant decrease in p-S473 AKT levels in an in vitro decidualization model, as well as the attenuation of decidual marker expression in ESCs by SC79 (a synthetic compound that suppresses $\mathrm{PH}_{\mathrm{AKT}}{ }^{-}$ GFP plasma membrane translocation but enhances AKT phosphorylation and activation in the cytosol), in the present study, verified the correlation of reduced p-S473 AKT with ESC decidualization.

The underlying mechanism and factors responsible for the decrease of $p$-S473 AKT during decidualization in ESCs remains unknown. The decrease in AKT activity in decidualization is isoform specific and site specific and does not involve ubiquitin-proteasome degradation (Fabi et al. 2017). Progesterone, which regulates the activation of AKT in many cell types and induces the decidualization of ESCs, may be involved. Our current study demonstrated that progesterone induced the expression of FKBP51 in ESCs. FKBP51 has recently been identified as a negative factor that enhances the phosphatase activity of PHLPP towards AKT (Gao et al. 2005). Overexpression or downregulation of FKBP51 leads to specific interactions between PHLPP isoforms and their corresponding AKT isoforms, suggesting that FKBP51 facilitates isoform-specific and site-specific regulation of AKT (Wang 2011). We performed two rescue experiments to assess the relationship between these crucial factors. The inhibition of decidualization marker proteins using FKBP51 shRNA was rescued by pcDNA3.1(+)/FKBP51, and the inhibition of decidualization proteins and the abnormal changes of proliferation ability induced by SC79 were rescued by FKBP51 overexpression. These results suggested that in the process of in vitro decidualization, the phosphorylation levels of $\mathrm{p}$-S473 AKT were regulated by the FKBP51 expression induced by progesterone. As shown in Fig. 5D, the FKBP51 upregulation induced by MPA can specifically increase the dephosphorylation of the Ser473 site in AKT and therefore alter downstream factors that affect decidualization.
Unfortunately, the sample size and methods of our study have their limits, weakening our conclusions. For now, we cannot explain the distinct roles of FKBP51 in mouse and human decidualization. Besides, we only detected the functions of FKBP51 in regulating the p-S473 AKT pathway in decidualization. There still are many pathways and factors having potential relationships with FKBP51 and decidualization that should be studied.

In summary, our findings strongly suggest that FKBP51 is a new indispensable element of ESC decidualization. Because FKBP51 expression is markedly induced in primary ESC during decidualization and the presence of FKBP51 is needed for adequate decidualization. In addition, the regulations of FKBP51 on p-S473 AKT pathway could explain the decrease of p-S473 AKT levels in in vitro decidualization, which were observed by numerous researchers. This study provides a foundation for more in-depth and detailed research to be performed in the future.

\section{Declaration of interest}

The authors declare that there is no conflict of interest that could be perceived as prejudicing the impartiality of the research reported.

\section{Funding}

This study was funded by The National Key Research and Development Program of China (2017YFSF080004).

\section{Author contribution statement}

Prof. Yueran Zhao designed and supervised the study. Muyun Wei designed and performed most of the tests, analysed the data and wrote the manuscript. Lei Yan provided help collecting the patient tissues. Ying Gao, Bingru Lu, Yulian Jiao, Xiaowen Liu, Bin Cui, Shengnan Hu, Linying Sun and Jing Dong performed parts of the experiments. All authors reviewed the paper and approved the final manuscript.

\section{References}

Bombail V, Gibson DA, Collins F, MacPherson S, Critchley HO \& Saunders PT 2010 A role for the orphan nuclear receptor estrogenrelated receptor alpha in endometrial stromal cell decidualization and expression of genes implicated in energy metabolism. Journal of Clinical Endocrinology and Metabolism 95 E224-E228. (https://doi.org/10.1210/ jc.2010-0154)

Bourdiec A, Ahmad SF, Lachhab A \& Akoum A 2016 Regulation of inflammatory and angiogenesis mediators in a functional model of decidualized endometrial stromal cells. Reproductive BioMedicine Online 32 85-95. (https://doi.org/10.1016/j.rbmo.2015.09.011)

Buzzio OL, Lu Z, Miller CD, Unterman TG \& Kim J 2006 FOXO1A differentially regulates genes of decidualization. Endocrinology 147 3870-3876. (https://doi.org/10.1210/en.2006-0167)

Caldwell JM, Blanchard C, Collins MH, Putnam PE, Kaul A, Aceves SS, Bouska CA \& Rothenberg ME 2010 Glucocorticoid-regulated genes in eosinophilic esophagitis: a role for FKBP51. Journal of Allergy and 
Clinical Immunology 125 879.e8-888.e8. (https://doi.org/10.1016/j. jaci.2010.01.038)

Cha J, Sun X \& Dey SK 2012 Mechanisms of implantation: strategies for successful pregnancy. Nature Medicine 18 1754-1767. (https://doi. org/10.1038/nm.3012)

Chen L, Lei K, Malawana J, Yulia A, Sooranna SR, Bennett PR, Liang Z, Grammatopoulos D \& Johnson MR 2014 Cyclic AMP enhances progesterone action in human myometrial cells. Molecular and Cellular Endocrinology 382 334-343. (https://doi.org/10.1016/j. mce.2013.10.018)

Cho H, Okada H, Tsuzuki T, Nishigaki A, Yasuda K \& Kanzaki H 2013 Progestin-induced heart and neural crest derivatives expressed transcript 2 is associated with fibulin-1 expression in human endometrial stromal cells. Fertility and Sterility 99 248-255. (https://doi.org/10.1016/j. fertnstert.2012.08.056)

Cinar O, Seval Y, Uz YH, Cakmak H, Ulukus M, Kayisli UA \& Arici A 2009 Differential regulation of Akt phosphorylation in endometriosis. Reproductive BioMedicine Online $19 \quad 864-871 . \quad$ (https://doi. org/10.1016/j.rbmo.2009.10.001)

Curry TE Jr \& Osteen KG 2003 The matrix metalloproteinase system: changes, regulation, and impact throughout the ovarian and uterine reproductive cycle. Endocrine Reviews 24 428-465. (https://doi. org/10.1210/er.2002-0005)

Das SK 2009 Cell cycle regulatory control for uterine stromal cell decidualization in implantation. Reproduction 137 889-899. (https:// doi.org/10.1530/REP-08-0539)

Dey SK, Lim H, Das SK, Reese J, Paria BC, Daikoku T \& Wang H 2004 Molecular cues to implantation. Endocrine Reviews 25 341-373. (https://doi.org/10.1210/er.2003-0020)

Fabi F, Grenier K, Parent S, Adam P, Tardif L, Leblanc V \& Asselin E 2017 Regulation of the PI3K/Akt pathway during decidualization of endometrial stromal cells. PLOS ONE 12 e0177387. (https://doi. org/10.1371/journal.pone.0177387)

Gao T, Furnari F \& Newton AC 2005 PHLPP: a phosphatase that directly dephosphorylates Akt, promotes apoptosis, and suppresses tumor growth. Molecular Cell 18 13-24. (https://doi.org/10.1016/j. molcel.2005.03.008)

Guzeloglu Kayisli O, Kayisli UA, Basar M, Semerci N, Schatz F \& Lockwood CJ 2015 Progestins upregulate FKBP51 expression in human endometrial stromal cells to induce functional progesterone and glucocorticoid withdrawal: implications for contraceptive- associated abnormal uterine bleeding. PLOS ONE 10 e0137855. (https://doi. org/10.1371/journal.pone.0137855)

Hirota Y, Daikoku T, Tranguch S, Xie H, Bradshaw HB \& Dey SK 2010 Uterine-specific p53 deficiency confers premature uterine senescence and promotes preterm birth in mice. Journal of Clinical Investigation $\mathbf{1 2 0}$ 803-815. (https://doi.org/10.1172/JCl40051)

Hubler TR, Denny WB, Valentine DL, Cheung-Flynn J, Smith DF \& Scammell JG 2003 The FK506-binding immunophilin FKBP51 is transcriptionally regulated by progestin and attenuates progestin responsiveness. Endocrinology 144 2380-2387. (https://doi.org/10.1210/ en.2003-0092)

Jaaskelainen T, Makkonen H \& Palvimo JJ 2011 Steroid upregulation of FKBP51 and its role in hormone signaling. Current Opinion in Pharmacology 11 326-331. (https://doi.org/10.1016/j. coph.2011.04.006)

Kim JJ, Buzzio OL, Li S \& Lu Z 2005 Role of FOXO1A in the regulation of insulin-like growth factor-binding protein-1 in human endometrial cells: interaction with progesterone receptor. Biology of Reproduction 73 833-839. (https://doi.org/10.1095/biolreprod.105.043182)

Kuroda K, Venkatakrishnan R, James S, Sucurovic S, Mulac-Jericevic B, Lucas ES, Takeda S, Shmygol A, Brosens JJ \& Quenby S 2013 Elevated periimplantation uterine natural killer cell density in human endometrium is associated with impaired corticosteroid signaling in decidualizing stromal cells. Journal of Clinical Endocrinology and Metabolism 98 4429-4437. (https://doi.org/10.1210/jc.2013-1977)

Labied S, Kajihara T, Madureira PA, Fusi L, Jones MC, Higham JM, Varshochi R, Francis JM, Zoumpoulidou G, Essafi A et al. 2006 Progestins regulate the expression and activity of the forkhead transcription factor FOXO1 in differentiating human endometrium. Molecular Endocrinology 20 35-44. (https://doi.org/10.1210/me.2005-0275)
Li H, Li H, Bai L \& Yu H 2014 Lefty inhibits in vitro decidualization by regulating P57 and cyclin D1 expressions. Cell Biochemistry and Function 32 657-664. (https://doi.org/10.1002/cbf.3069)

Makkonen H, Kauhanen M, Paakinaho V, Jaaskelainen T \& Palvimo JJ 2009 Long-range activation of FKBP51 transcription by the androgen receptor via distal intronic enhancers. Nucleic Acids Research 37 4135-4148. (https://doi.org/10.1093/nar/gkp352)

Matsuoka A, Kizuka F, Lee L, Tamura I, Taniguchi K, Asada H, Taketani T, Tamura H \& Sugino N 2010 Progesterone increases manganese superoxide dismutase expression via a cAMP-dependent signaling mediated by noncanonical Wnt5a pathway in human endometrial stromal cells. Journal of Clinical Endocrinology and Metabolism 95 E291-E299. (https://doi.org/10.1210/jc.2010-0619)

Memarzadeh S, Zong Y, Janzen DM, Goldstein AS, Cheng D, Kurita T, Schafenacker AM, Huang J \& Witte ON 2010 Cell-autonomous activation of the PI3-kinase pathway initiates endometrial cancer from adult uterine epithelium. PNAS 107 17298-17303. (https://doi. org/10.1073/pnas.1012548107)

Mori M, Kitazume M, Ose R, Kurokawa J, Koga K, Osuga Y, Arai S \& Miyazaki T 2011 Death effector domain-containing protein (DEDD) is required for uterine decidualization during early pregnancy in mice. Journal of Clinical Investigation 121 318-327. (https://doi.org/10.1172/ JCl44723)

Pei H, Li L, Fridley BL, Jenkins GD, Kalari KR, Lingle W, Petersen G, Lou Z \& Wang L 2009 FKBP51 affects cancer cell response to chemotherapy by negatively regulating Akt. Cancer Cell 16 259-266. (https://doi. org/10.1016/j.ccr.2009.07.016)

Rearte B, Maglioco A, Balboa L, Bruzzo J, Landoni VI, Laborde EA, Chiarella P, Ruggiero RA, Fernandez GC \& Isturiz MA 2010 Mifepristone (RU486) restores humoral and T cell-mediated immune response in endotoxin immunosuppressed mice. Clinical and Experimental Immunology 162 568-577. (https://doi.org/10.1111/ j.1365-2249.2010.04262.x)

Salker MS, Christian M, Steel JH, Nautiyal J, Lavery S, Trew G, Webster Z, Al-Sabbagh M, Puchchakayala G, Foller M et al. 2011 Deregulation of the serum- and glucocorticoid-inducible kinase SGK1 in the endometrium causes reproductive failure. Nature Medicine 17 1509-1513. (https:// doi.org/10.1038/nm.2498)

Sinars CR, Cheung-Flynn J, Rimerman RA, Scammell JG, Smith DF \& Clardy J 2003 Structure of the large FK506-binding protein FKBP51, an Hsp90-binding protein and a component of steroid receptor complexes. PNAS 100 868-873. (https://doi.org/10.1073/pnas.0231020100)

Stechschulte LA, Qiu B, Warrier M, Hinds TD Jr, Zhang M, Gu H, Xu Y, Khuder SS, Russo L, Najjar SM et al. 2016 FKBP51 null mice are resistant to diet-induced obesity and the PPARgamma agonist rosiglitazone. Endocrinology 157 3888-3900. (https://doi.org/10.1210/en.2015-1996)

Storer CL, Dickey CA, Galigniana MD, Rein T \& Cox MB 2011 FKBP51 and FKBP52 in signaling and disease. Trends in Endocrinology and Metabolism 22 481-490. (https://doi.org/10.1016/j.tem.2011.08.001)

Strowitzki T, Germeyer A, Popovici R \& von Wolff M 2006 The human endometrium as a fertility-determining factor. Human Reproduction Update 12 617-630. (https://doi.org/10.1093/humupd/dml033)

Sugino N, Kashida S, Takiguchi S, Nakamura Y \& Kato H 2000 Induction of superoxide dismutase by decidualization in human endometrial stromal cells. Molecular Human Reproduction 6 178-184. (https://doi. org/10.1093/molehr/6.2.178)

Takano M, Lu Z, Goto T, Fusi L, Higham J, Francis J, Withey A, Hardt J, Cloke B, Stavropoulou AV et al. 2007 Transcriptional cross talk between the forkhead transcription factor forkhead box O1A and the progesterone receptor coordinates cell cycle regulation and differentiation in human endometrial stromal cells. Molecular Endocrinology 21 2334-2349. (https://doi.org/10.1210/me.2007-0058)

Tan J, Raja S, Davis MK, Tawfik O, Dey SK \& Das SK 2002 Evidence for coordinated interaction of cyclin D3 with p21 and cdk6 in directing the development of uterine stromal cell decidualization and polyploidy during implantation. Mechanisms of Development 111 99-113. (https:// doi.org/10.1016/S0925-4773(01)00614-1)

Toyofuku A, Hara T, Taguchi T, Katsura Y, Ohama K \& Kudo Y 2006 Cyclic and characteristic expression of phosphorylated Akt in human endometrium and decidual cells in vivo and in vitro. Human Reproduction 21 1122-1128. (https://doi.org/10.1093/humrep/dei454) 
Tranguch S, Smith DF \& Dey SK 2006 Progesterone receptor requires a co-chaperone for signalling in uterine biology and implantation. Reproductive BioMedicine Online 13 651-660. (https://doi.org/10.1016/ S1472-6483(10)60655-4)

Tranguch S, Wang H, Daikoku T, Xie H, Smith DF \& Dey SK 2007 FKBP52 deficiency-conferred uterine progesterone resistance is genetic background and pregnancy stage specific. Journal of Clinical Investigation 117 1824-1834. (https://doi.org/10.1172/JCI31622)

Velarde MC, Aghajanova L, Nezhat CR \& Giudice LC 2009 Increased mitogen-activated protein kinase kinase/extracellularly regulated kinase activity in human endometrial stromal fibroblasts of women with endometriosis reduces $3^{\prime}, 5^{\prime}$-cyclic adenosine 5'-monophosphate inhibition of cyclin D1. Endocrinology 150 4701-4712. (https://doi. org/10.1210/en.2009-0389)

Wang L 2011 FKBP51 regulation of AKT/protein kinase B phosphorylation. Current Opinion in Pharmacology 11 360-364. (https://doi. org/10.1016/j.coph.2011.03.008)

Wang H \& Dey SK 2006 Roadmap to embryo implantation: clues from mouse models. Nature Reviews Genetics 7 185-199. (https://doi. org/10.1038/nrg1808)

Wardell SE, Narayanan R, Weigel NL \& Edwards DP 2010 Partial agonist activity of the progesterone receptor antagonist RU486 mediated by an amino-terminal domain coactivator and phosphorylation of serine 400 . Molecular Endocrinology 24 335-345. (https://doi.org/10.1210/ me.2008-0081)

Weimar CH, Macklon NS, Post Uiterweer ED, Brosens JJ \& Gellersen B 2013 The motile and invasive capacity of human endometrial stromal cells: implications for normal and impaired reproductive function. Human Reproduction Update 19 542-557. (https://doi.org/10.1093/ humupd/dmt025)
Xu L, Zhu Y, Xu J, Wu K, Li J, Xu W, Liu H, Wang S, Yin H, Chen L et al. 2012 Notch1 activation promotes renal cell carcinoma growth via PI3K/ Akt signaling. Cancer Science 103 1253-1258. (https://doi.org/10.1111/ j.1349-7006.2012.02291.x)

Yang Z, Wolf IM, Chen H, Periyasamy S, Chen Z, Yong W, Shi S, Zhao W, Xu J, Srivastava A et al. 2006 FK506-binding protein 52 is essential to uterine reproductive physiology controlled by the progesterone receptor A isoform. Molecular Endocrinology 20 2682-2694. (https://doi. org/10.1210/me.2006-0024)

Yang H, Zhou Y, Edelshain B, Schatz F, Lockwood CJ \& Taylor HS 2012 FKBP4 is regulated by HOXA10 during decidualization and in endometriosis. Reproduction 143 531-538. (https://doi.org/10.1530/ REP-11-0438)

Yin X, Pavone ME, Lu Z, Wei J \& Kim JJ 2012 Increased activation of the PI3K/AKT pathway compromises decidualization of stromal cells from endometriosis. Journal of Clinical Endocrinology and Metabolism 97 E35-E43. (https://doi.org/10.1210/jc.2011-1527)

Yoshino O, Osuga Y, Hirota Y, Koga K, Yano T, Tsutsumi O \& Taketani Y 2003 Akt as a possible intracellular mediator for decidualization in human endometrial stromal cells. Molecular Human Reproduction 9 265-269. (https://doi.org/10.1093/molehr/gag035)

Received 14 October 2017

First decision 13 November 2017

Revised manuscript received 13 January 2018

Accepted 22 January 2018 